\title{
EFFECT OF THE VAGAL AND SPLANCHNIC NERVE STIMULATION ON THE RELEASE OF SOMATOSTATIN, PANCREATIC POLYPEPTIDE, GLUCAGON AND INSULIN
}

\author{
AKIO KANETO ${ }^{1}$, SHOJI KAWAZU ${ }^{1}$, HARUKO SATO ${ }^{2}$, TOSHIO KANEKO ${ }^{3}$, CHIZUKO \\ YANAIHARA $^{2}$, NOBORU YANAIHARA ${ }^{2}$ and KINORI KOSAKA ${ }^{1}$ \\ ${ }^{1}$ The Third Department of Internal Medicine, Faculty of Medicine, University of Tokyo, Tokyo 113, \\ ${ }^{2}$ Laboratory of Bioorganic Chemistry, Shizuoka College of Pharmacy, Shizuoka 422, and ${ }^{3}$ The Third \\ Department of Internal Medicine, Yamaguchi University School of Medicine, Ube 755, Japan
}

\begin{abstract}
Electrical stimulation of the distal cut end of the dorsal vagus and the left splanchnic nerves was performed at the diaphragmatic level in anesthetized dogs to study effects on islet hormone output from the pancreas. Stimulation of the vagus nerve increased both blood flow and plasma concentrations of somatostatin, pancreatic polypeptide (PP), glucagon and insulin in the cranial pancreaticoduodenal vein, resulting in a greater augmentation of output of these hormones. A significant enhancement was seen in femoral arterial plasma levels of all these hormones, and plasma glucose concentration rose gradually during vagal stimulation. Atropinization decreased the basal output of PP, glucagon and insulin and abolished the augmentation in output of overall pancreatic islet hormones in response to vagal stimulation. During stimulation of the splanchnic nerve, an abrupt transitory fall occurred and was followed by a significant increase in pancreatic vein blood flow. This increase was accompanied by a significant elevation of hematocrit, resulting in a nonsignificant increase in pancreatic plasma flow. Splanchnic nerve stimulation raised the output of somatostatin and glucagon after an initial fall, but output of PP and insulin remained unchanged after an initial decrease in the occurrence of marked hyperglycemia during stimulation. Insulin output showed a rebound after the end of the stimulus whereas PP output did not. A significant rise was observed in femoral arterial plasma glucagon, but other islet hormones did not reveal any change during splanchnic nerve stimulation. These results indicate that physiological activation of both vagus and splanchnic nerves may regulate secretion of not only glucagon and insulin but also somatostatin and PP from the pancreas in the dog.
\end{abstract}

KEY WORDS vagus nerve stimulation / splanchnic nerve stimulation/pancreatic vein blood flow / plasma somatostatin-like immunoreactivity / plasma immunoreactive pancreatic polypeptide / plasma immunoreactive glucagon / plasma immunoreactive insulin / plasma glucose

Recent endocrinological progress has shown that cells secreting active peptides such as somatostatin $(2,7,27,30)$ and pancreatic polypeptide (PP) $(1,5,25)$ are localized in pancreatic islets in addition to the A and B cells, and that some nerve endings or ganglia in the islet contain vesicles in which vasoactive intestinal polypeptide-like immunoreactivity $(10,11,26)$ and gastrin-like immunoreactivity (41) have been identified. However, very few data are available with regard to neural regulation in somatostatin secretion from the pancreas (13). Whether 
neural control of islet hormone secretion is performed solely cholinergically and adrenergically or any peptidergic transmission or modulation is associated with their secretion is also problematic.

The authors have already reported effects of electrical stimulation of the vagus (19) and splanchnic nerves (20) on pancreatic glucagon and insulin secretion in the dog. The present investigation was undertaken in order to study neuroendocrine mechanisms in somatostatin and PP secretion as well as glucagon and insulin release, under circumstances where both pancreaticoduodenal vein blood flow and plasma concentrations of somatostatin, PP, glucagon and insulin could be measured simultaneously in anesthetized dogs.

\section{MATERIALS AND METHODS}

Twenty-three mongrel dogs weighing 14.5 to 27.2 $\mathrm{kg}$ were used under pentobarbital anesthesia after an overnight fast. After midline laparotomy, the dorsal vagus nerve was exposed by downward traction on the cardiac portion of the stomach and cut at the supradiaphragmatic level in sixteen animals. The left splanchnic nerve was sectioned at approximately $2 \mathrm{~cm}$ above the adrenal gland, below the attachment of the diaphragm in the other seven dogs. In order to prevent any inflow of blood from the adrenals, the lumboadrenal veins which run through the adrenals were bilaterally ligated proximal and peripheral to the glands, instead of adrenalectomizing the dogs which might destroy surrounding and underlying nervous filaments. The distal cut end of the dorsal vagus or splanchnic nerve was threaded through a small hole in electrode platelets, and secured to an electrode holder of dental acrylic resin embedding the platelets. The electrode body was wrapped in a sheet of silk cloth to minimize contamination by blood. An extracorporeal pancreatic blood circuit was made between the cranial pancreaticoduodenal vein and portal vein, as previously described (21). Blood effluent from the pancreas via the shunt was anticoagulated by infusion of heparin in saline in a small volume (40-50 U/min) through a polyethylene catheter into the caudal pancreaticoduodenal vein. The right gastroepiploic vessels were ligated at the pyloric level, and the abdominal wall was kept closed until completion of the experiment. The femoral artery was cannulated for simultaneous sampling. A period of $1 \mathrm{hr}$ was allowed to elapse between the surgical preperation and the first sampling. Pancreatic vein blood flow was measured by collecting timed blood samples after interruption of the extracorporeal shunt and adjusting back pressure in the catheter to portal venous pressure, using the distal catheter as a manometer. Stimulation of the dorsal vagus and left splanchnic nerves was performed in 8 and 7 dogs, respectively, with a constant current stimulator using square waves of $8 \mathrm{~mA}$, $2 \mathrm{msec}$ and $50 \mathrm{cps}$ for $10 \mathrm{~min}$. Blood samples were obtained at $-6,-3,0,3,6$ and $10 \mathrm{~min}$ after the start of stimulation and 5, 10, 30 and 60 min after its termination, in chilled tubes containing ca $200 \mu \mathrm{g}(1,400 \mathrm{KIU})$ of Trasylol (Bayer, Leverkusen, West Germany). The sampling at $0 \mathrm{~min}$ was done at the first $15-30 \mathrm{sec}$ after initiation of stimulation. In the other series of 8 animals, atropine sulfate was injected into the femoral vein at a dose of $100 \mu \mathrm{g} / \mathrm{kg}$ at -9 min prior to the onset of stimulation of the vagus nerve, immediately after two successive samplings. Further blood samples were obtained in a sequence similar to that in the nonpretreated series.

Plasma somatostatin-like immunoreactivity (SLI) levels were assayed by the method of Harris et al. (14). ${ }^{125} \mathrm{I}-N^{\alpha}$-tyrosil-somatostatin was used as tracer (22). Rabbit antisomatostatin serum No. R101 was employed which had been kindly donated by Dr A. Arimura, VA Hospital, New Orleans, La. Plasma immunoreactive pancreatic polypeptide (IRP) levels were measured by a polyethylene glycol method $(6,22)$. Standard bPP (Lot 615-D632-86) and rabbit anti-bPP serum (Lot 615-R110-146-10) were generously supplied by Dr R. E. Chance, Lilly Research Laboratories, Indianapolis, Indiana. ${ }^{125} \mathrm{I}-N^{\alpha_{-}}$ tyrosil-somatostatin or ${ }^{125} \mathrm{I}-\mathrm{bPP}$ was not displaced from each antibody by any other pancreatic islet hormones used as standards at molar concentrations 10-20 times those of synthetic somatostatin or bPP. Plasma immunoreactive glucagon (IRG) levels were assayed by a slight modification of the chromatographic procedure of Ørskov et al. (31). The rabbit antiglucagon serum $30 \mathrm{~K}$ was used. Plasma immunoreactive insulin (IRI) levels were measured by a modification of the method of Morgan and Lazarow (29) using dog insulin (Lot H6264, Novo Research Institute, Copenhagen) as a standard.

The hormone output in pancreatic venous blood was calculated as the product of individual hormone concentrations and plasma flow in the samples. Plasma glucose concentrations in the femoral artery were determined by a glucose oxidase method (45). The Wilcoxon two-tailed 
signed-rank test was employed for the statistical analysis of the difference of means in paired samples. Data are expressed as mean $\pm \mathrm{SEM}$.

\section{RESULTS}

\section{Effect of Vagus Nerve Stimulation}

Electrical stimulation of the distal cut end of the dorsal vagus nerve caused a rapid increase in pancreatic vein blood flow from the prestimulatory level of $30.5 \pm 2.7$ to a peak of $45.9 \pm 5.1$ $\mathrm{ml} / \mathrm{min}$ at $6 \mathrm{~min}$ after initiation of the stimulus (Fig. 1). The percent increase of the blood flow markedly exceeded that of the hematocrit, resulting in an augmentation in pancreatic vein plasma flow.

Mean pancreatic effluent plasma concentration of SLI showed an immediate rise from the prestimulatory level of $365 \pm 90$ to a peak of $957 \pm 337 \mathrm{pg} / \mathrm{ml}$ at $6 \mathrm{~min}$ during vagal stimulation, and remained elevated for the remainder of the experiment (Fig. 1). Mean pancreatic output of SLI was promptly elevated from $6.454 \pm 2.112$ to a peak of $21.199 \pm 8.546 \mathrm{ng} / \mathrm{min}$, returning slowly to the prestimulatory level within an hour. Mean plasma SLI level in the

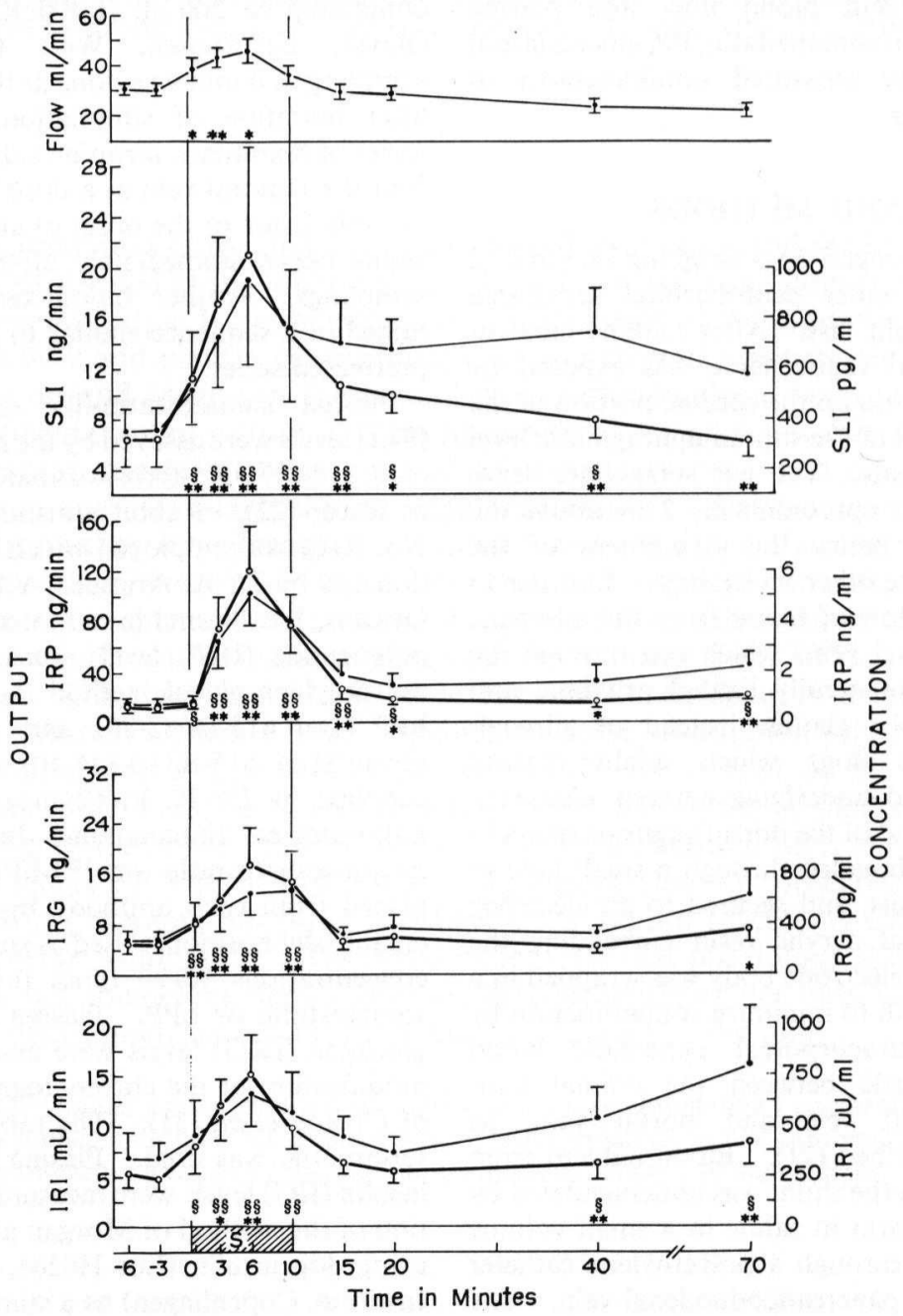

Fig. 1 Effect of stimulation of the dorsal vagus nerve (S) on pancreatic vein blood flow and pancreatic venous plasma concentrations and output (open circles) of SLI, IRP, IRG and IRI $(n=8$, mean \pm SEM). Asterisks refer to statistical significance of -3 min value vs. poststimulation values, except for those of output, which are indicated by $\S$; singly they indicate the difference at the $P<0.05$ level, and doubled at the $P<0.01$ level. 
femoral artery rose retardedly during stimulation (Fig. 2).

Mean pancreatic venous plasma level of IRP was raised from $760 \pm 185$ to a peak of $5,187 \pm$ $1,311 \mathrm{pg} / \mathrm{ml}$ at $6 \mathrm{~min}$ during stimulation, and did not subside to the base line throughout the experiment (Fig. 1). Mean pancreatic output of IRP increased rapidly from $11.157 \pm 1.874$ to a peak of $120.035 \pm 35.909 \mathrm{ng} / \mathrm{min}$ at $6 \mathrm{~min}$, returning to the base line within $30 \mathrm{~min}$. Femoral arterial plasma level of IRP was markedly raised during stimulation (Fig. 2).

Mean pancreatic venous plasma concentration of IRG rose from the prestimulatory level of $284 \pm 70$ to a peak of $682 \pm 186 \mathrm{pg} / \mathrm{ml}$ at $10 \mathrm{~min}$ during vagal stimulation, and subsided rapidly (Fig. 1). Mean pancreatic output of IRG increased from $4.716 \pm 1.051$ to a peak of 17.380 $\pm 5.962 \mathrm{ng} / \mathrm{min}$ at $6 \mathrm{~min}$. Mean arterial plasma IRG rose significantly during stimulation (Fig. 2).

Mean pancreatic effluent plasma level of IRI was elevated from $329 \pm 104$ to a peak of $670 \pm 171 \mu \mathrm{U} / \mathrm{ml}$ at $6 \mathrm{~min}$, transiently subsided, and then showed a gradual increase toward the end of the experiment (Fig. 1). Mean pancreatic output of IRI increased from $4.890 \pm 1.173$ to a peak of $15.214 \pm 3.859 \mathrm{mU} / \mathrm{min}$ at $6 \mathrm{~min}$ during stimulation. Mean arterial plasma IRI rose retardedly (Fig. 2).

Mean arterial plasma glucose showed a

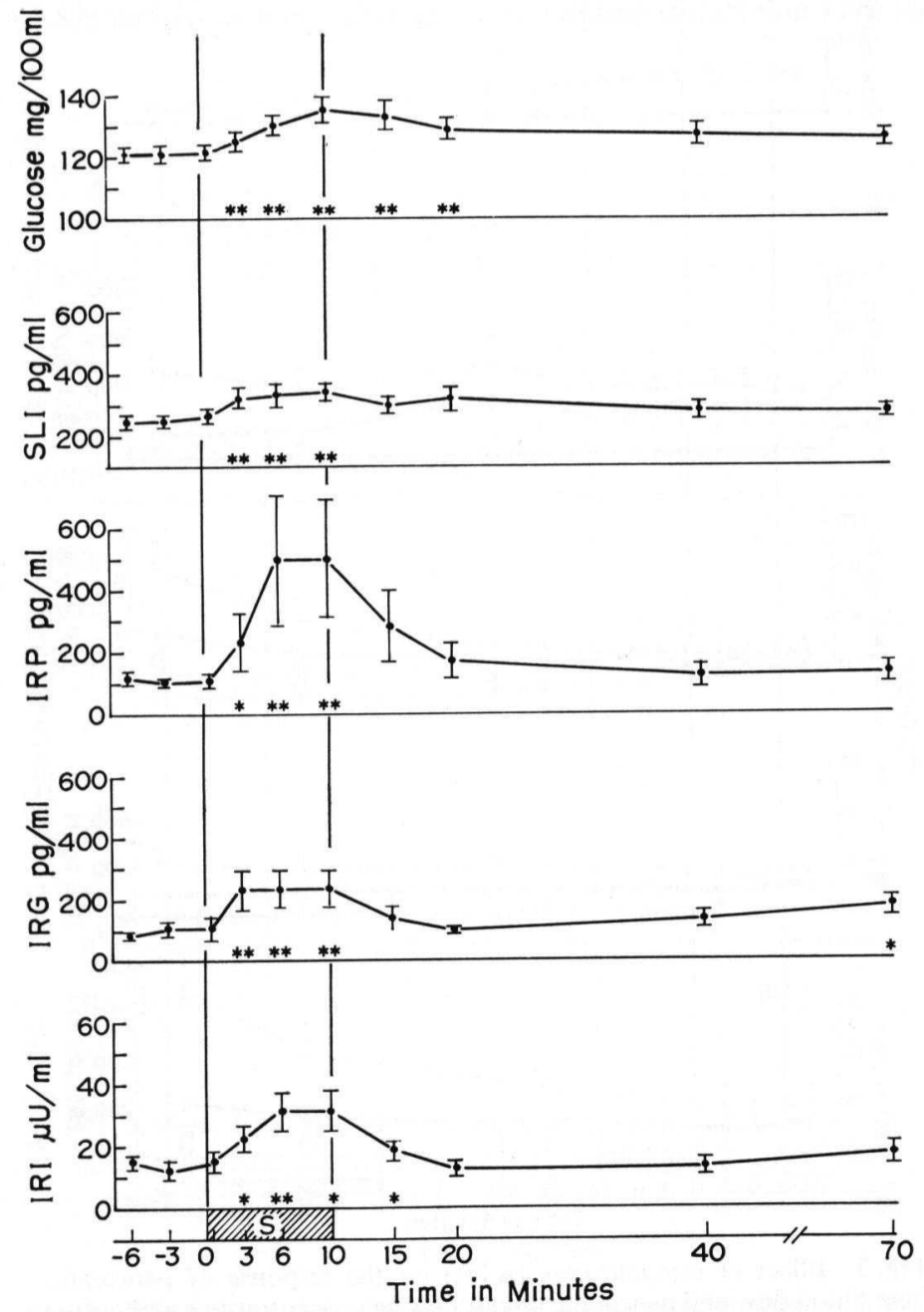

Fig. 2 Effect of stimulation of the dorsal vagus nerve (S) on femoral arterial plasma concentrations of glucose, SLI, IRP, IRG and IRI $(\mathrm{n}=8$, mean \pm SEM $)$. Asterisks refer to statistical significance of -3 min value vs. poststimulation values; singly they indicate the difference at the $P<0.05$ level, and doubled at the $P<0.01$ level. 
gradual rise from $121.6 \pm 2.9$ to a peak of $135.1 \pm$ $4.5 \mathrm{mg} / 100 \mathrm{ml}$ at $10 \mathrm{~min}$ during vagal stimulation (Fig. 2).

\section{Effect of Atropinization on the Responses to Vagal Stimulation}

A significant decrease was seen in mean pancreatic output of IRP, IRG and IRI at 6 min after the intravenous injection of atropine prior to vagal stimulation (Fig. 3). A significant elevation was not observed either in mean pancreatic venous blood flow or in mean pancreatic output of SLI, IRP, IRG and IRI during vagal stimula- tion preceded by the injection of atropine. Mean pancreatic effluent plasma levels of IRP and IRI showed a gradual increase at and after the end of vagal stimulation, and their output also increased slowly toward the end of experiments. A poststimulatory gradual rise was seen in the arterial plasma level of glucose, IRP and IRG (Fig. 4).

\section{Effect of Splanchnic Nerve Stimulation}

Pancreatic vein blood flow decreased immediately and transiently from $26.0 \pm 3.4$ to a nadir of $16.5 \pm 2.6 \mathrm{ml} / \mathrm{min}$ after the start of the electrical

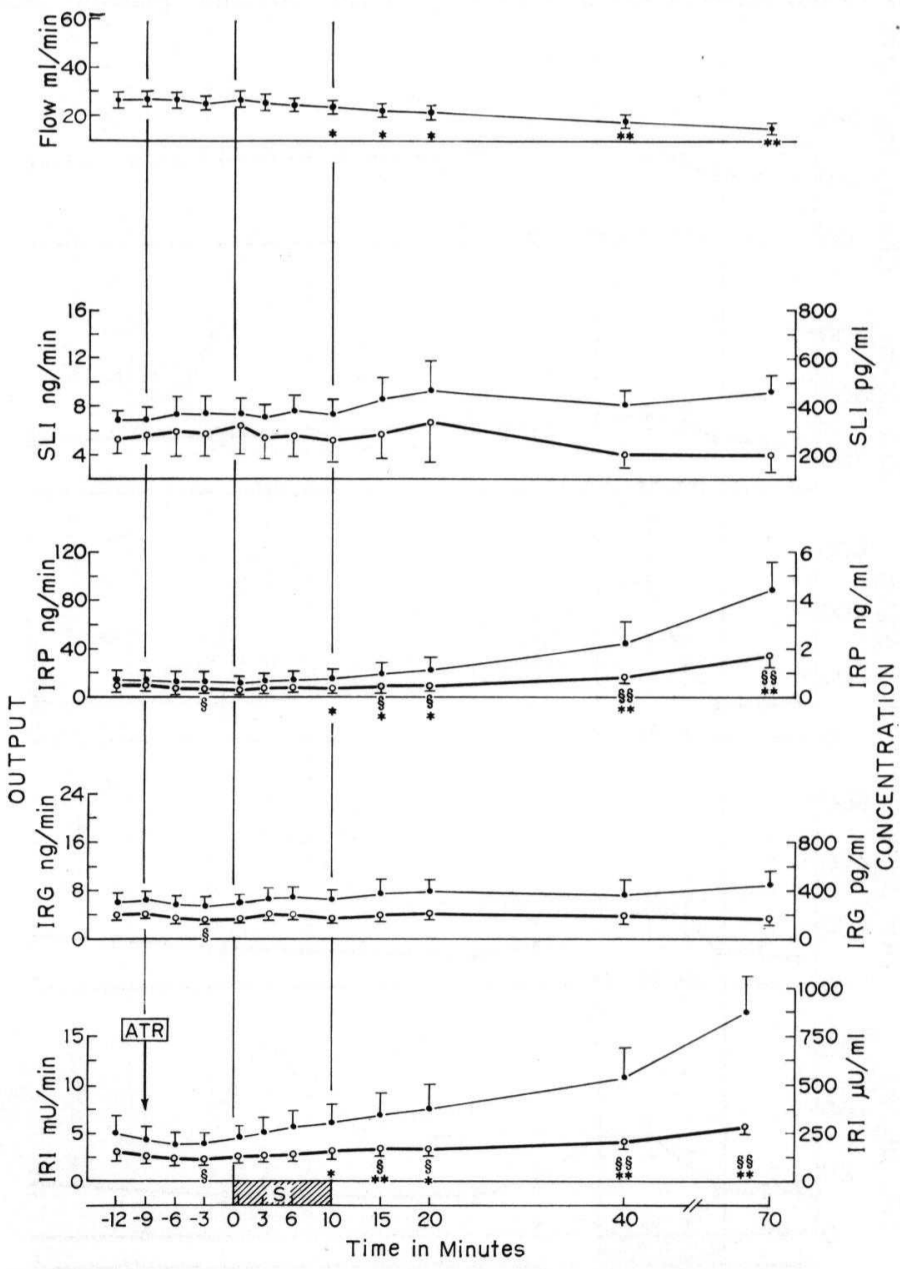

Fig. 3 Effect of atropinization (ATR) on the response of pancreatic vein blood flow and pancreatic venous plasma concentrations and output (open circles) of SLI, IRP, IRG and IRI to vagal stimulation (S) $(n=8$, mean \pm SEM). Asterisks refer to statistical significance of $-9 \mathrm{~min}$ value vs. $-3 \mathrm{~min}$ value, and of $-3 \mathrm{~min}$ value vs. poststimulation values, except for those of output, which are indicated by $\S$; singly they indicate the difference at the $P<0.05$ level, and doubled at the $P<0.01$ level. 
stimulation of the distal cut end of the splanchnic nerve, and then increased to a peak of $37.1 \pm 3.7$ $\mathrm{ml} / \mathrm{min}$ at $6 \mathrm{~min}$ during stimulation (Fig. 5). A marked increase of hematocrit values in pancreatic effluent offset an increase in pancreatic blood flow, resulting in a nonsignificant augmentation of pancreatic venous plasma flow during stimulation.

Mean pancreatic venous plasma level of SLI showed an oscillatory elevation during and after splanchnic nerve stimulation, and remained elevated for the remainder of the experiment (Fig. 5). Its output revealed a significant fall from $4.088 \pm 1.339$ to a nadir of $2.953 \pm 1.276$ $\mathrm{ng} / \mathrm{min}$ at $30 \mathrm{sec}$, and then a moderate increase to a peak of $7.520 \pm 2.825 \mathrm{ng} / \mathrm{min}$ at $6 \mathrm{~min}$ during stimulation. This increase was not reflected in the femoral arterial plasma level of SLI (Fig. 6).

Mean pancreatic effluent plasma concentration of IRP and its output fell rapidly and transiently after initiation of splanchnic nerve stimulation from $697 \pm 233$ to a nadir of $470 \pm 178 \mathrm{pg} / \mathrm{ml}$ and from $9.489 \pm 2.776$ to $4.520 \pm 1.807 \mathrm{ng} / \mathrm{min}$, respectively (Fig. 5). Then, they did not change during stimulation, showing a gradual elevation toward the end of the experiment. A significant alteration was not seen in arterial plasma IRP level (Fig. 6).

Mean pancreatic venous plasma concentration of IRG was augmented from the prestimulatory level of $263 \pm 37$ to a peak of $472 \pm 109 \mathrm{pg} / \mathrm{ml}$ at 6 min during stimulation, then subsiding rapidly

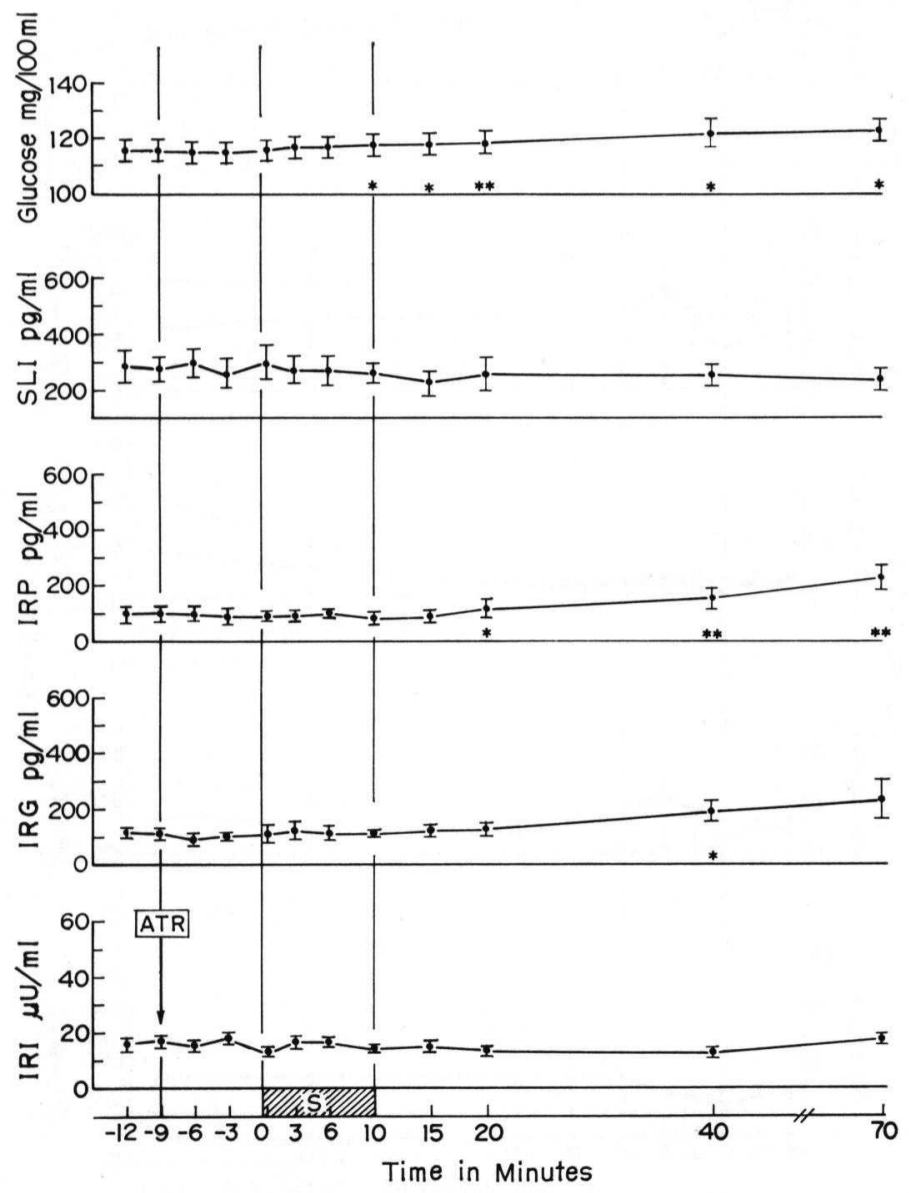

Fig. 4 Effect of atropinization (ATR) on the response of femoral arterial plasma concentrations of glucose, SLI, IRP, IRG and IRI to vagal stimulation (S) $(n=8$, mean $\pm S E M)$. Asterisks refer to statistical significance of $-9 \mathrm{~min}$ value vs. $-3 \mathrm{~min}$ value, and of $-3 \mathrm{~min}$ value vs. poststimulation values; singly they indicate the difference at the $P<0.05$ level, and doubled at the $P<0.01$ level. 
(Fig. 5). Mean pancreatic output of IRG fell transiently from $3.958 \pm 0.925$ to a nadir of $2.366 \pm 0.466 \mathrm{ng} / \mathrm{min}$ at $30 \mathrm{sec}$, and then increased to a peak of $9.122 \pm 2.968 \mathrm{ng} / \mathrm{min}$ at $6 \mathrm{~min}$ during stimulation. This increase was reflected in arterial IRG level (Fig. 6).

Mean pancreatic effluent plasma level of IRI and its output showed a transitory fall at $30 \mathrm{sec}$ from $106 \pm 22$ to $84 \pm 20 \mu \mathrm{U} / \mathrm{ml}$ and from $1.521 \pm 0.459$ to $0.637 \pm 0.160 \mathrm{mU} / \mathrm{min}$, respectively, during stimulation (Fig. 5). They increased significantly after the stimulation, and remained elevated for the remainder of the experiment. Arterial plasma IRI did not change during the entire experiment (Fig. 6).

Mean arterial plasma level of glucose rose slowly from $110.2 \pm 3.9$ to a peak of $148.5 \pm 9.4$ $\mathrm{mg} / 100 \mathrm{ml}$ at $10 \mathrm{~min}$ during splanchnic nerve sitmulation, and returned to the base line within an hour.

\section{DISCUSSION}

There is general agreement concerning cholinergic $(18,21,36)$ and vagal $(3,19,36)$ influence on the A, B and PP-secreting cells in pancreatic islets, but there is only preliminary information regarding parasympathetic control of the $\mathrm{D}$ cell.

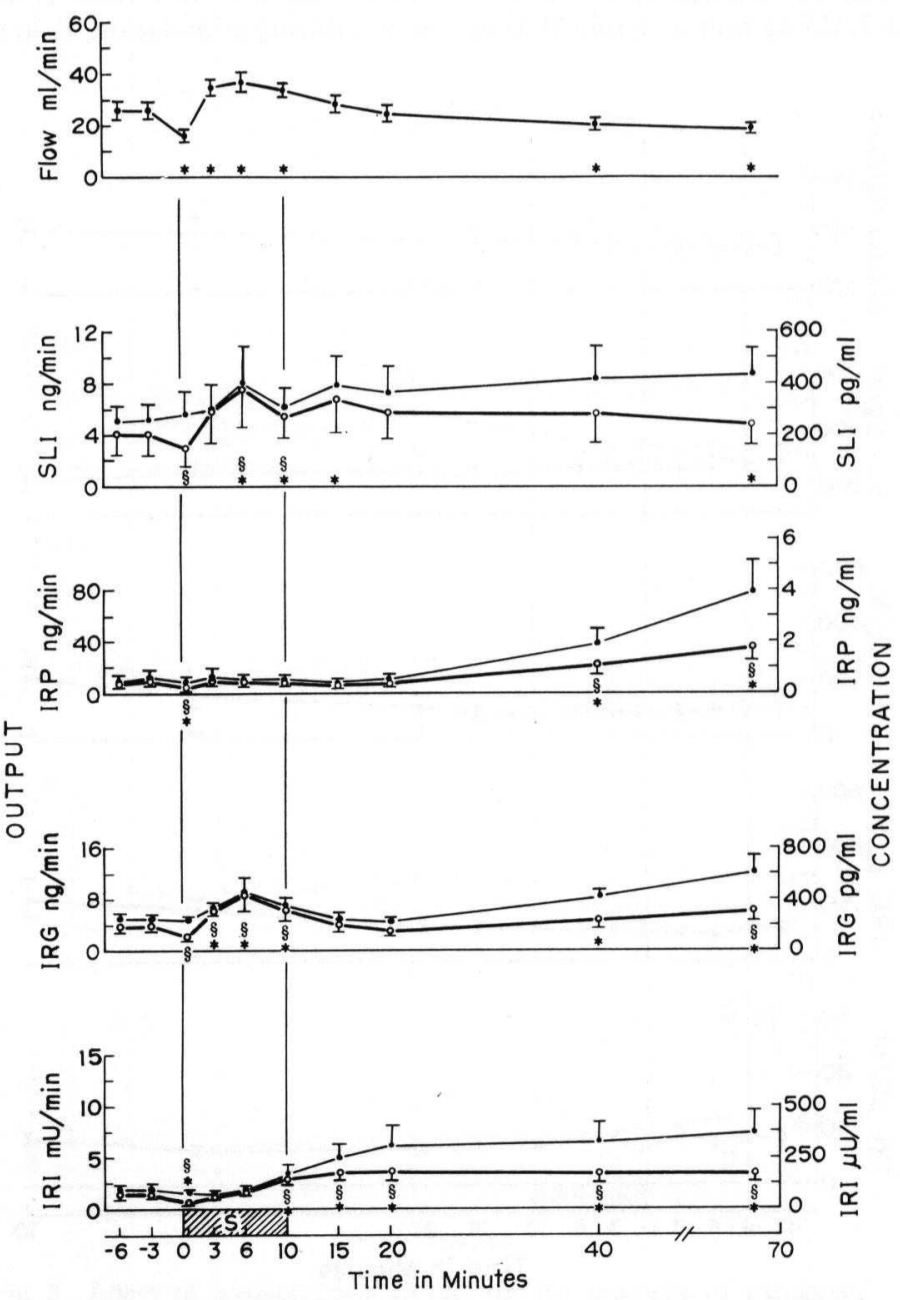

Fig. 5 Effect of stimulation of the left splanchnic nerve (S) on pancreatic vein blood flow and pancreatic venous plasma concentrations and output (open circles) of SLI, IRP, IRG and IRI ( $\mathrm{n}=7$, mean \pm SEM). Asterisks refer to statistical significance $(P<0.05)$ of -3 min value vs. poststimulation values, except for those of output, which are indicated by $\S$. 
The present study showed that electrical efferent stimulation of the dorsal vagus nerve resulted in an immediate increase in release of somatostatin and PP as well as of glucagon and insulin into the cranial pancreaticoduodenal vein, and that this response was totally abolished by atropinization.

Schwartz et al. (36) documented that electrical stimulation of the vagal nerves in anesthetized pigs caused a rapid increase in portal PP concentrations, that the response was inhibited by atropine, and that adrenergic $\alpha$ and $\beta$ blockade did not influence the release of $\mathrm{PP}$ in response to vagal stimulation. They found in man that truncal vagotomy eliminated an otherwise rapid increase in plasma PP levels during a meal, and that the secondary prolonged response was also significantly reduced (37). According to them, the afferent branch of the vagovagal reflex for PP release was activated by cephalic stimulation (38), and by gastric food- and distention-receptors (39). Thus, they concluded that vagal, cholinergic stimulation is a major regulator of PP secretion (36). In the present study we confirmed vagal control in PP release into the pancreatic vein electrophysiologically in anesthetized dogs.

In our experiments the right gastroepiploic vein was ligated before blood sampling began, so direct flow of active peptides released from the stomach into the pancreatic vein could be

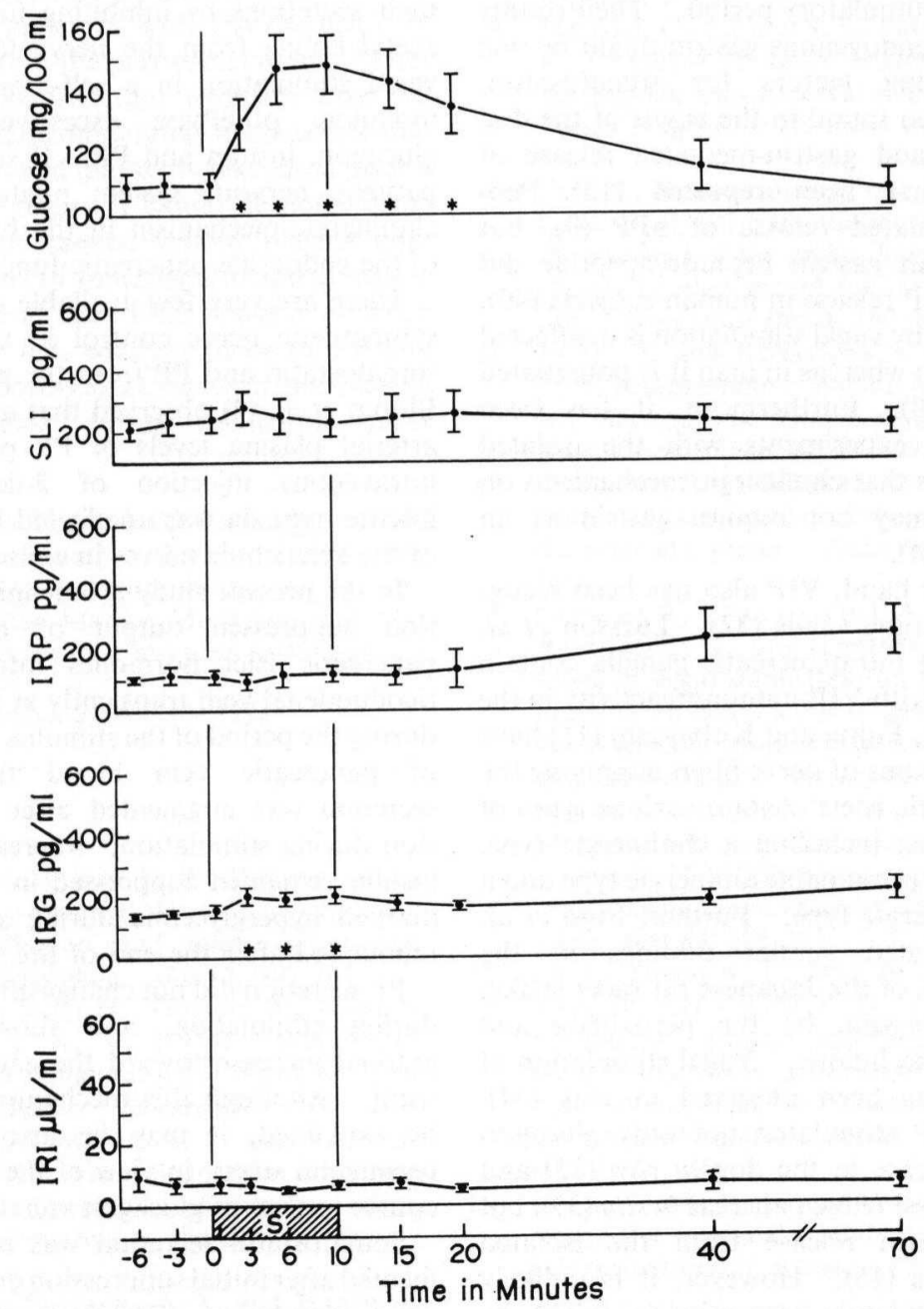

Fig. 6 Effect of stimulation of the left splanchnic nerve (S) on femoral arterial plasma concentrations of glucose, SLI, IRP, IRG and IRI $(\mathrm{n}=7$, mean $\pm \mathrm{SEM})$. Asterisks refer to statistical significance of -3 min value vs. poststimulation values. 
avoided. However, the pancreaticoduodenal effluent may have its draining source in the duodenum partially. Therefore, the increase in somatostatin output induced by vagal stimulation could not be attributed solely to pancreatic islets. The amount of somatostatin extractable from the duodenum, however, is far much smaller than from the pancreas in the dog and man (28). Guzman et al. (13) investigated the effect of electrical vagal stimulation on portal blood levels of gastrin, vasoactive intestinal peptide (VIP), somatostatin, and other exocrine pancreatic hormones in dogs. Gastrin, VIP and somatostatin increased significantly, and peak values for gastrin and VIP were found during stimulation whereas somatostatin peaked after the end of the stimulatory period. Their results suggested that endogenous gastrin might be one of the releasing factors for somatostatin. Gastrin has been found in the vagus of the dog and cat (41), and gastrin-mediated release of somatostatin has been reported (15). Pentagastrin stimulated release of hPP (9), but synthetic human gastrin heptadecapeptide did not stimulate PP release in human subjects (40). Gastrin release by vagal stimulation is unaffected by atropine (42) whereas in man it is potentiated by atropine (8). Furthermore, it has been obtained from experiments with the isolated canine pancreas that cholinergic mechanisms on the pancreas may not require gastrin as an intermediary (44).

On the other hand, VIP also has been recognized in the canine vagus (32). Larsson et al. (26) found that intrapancreatic ganglia contain many neurons with VIP-immunoreactivity in the dog. Recently, Fujita and Kobayashi (11) have reported that axons of nerve fibers supplying the canine pancreatic islets contain various types of synaptic vesicles, including a cholinergic type, two varieties of presumable aminergic type and a possible peptidergic type. Further, Fujii et al. (10) demonstrated similar findings in the pancreatic islets of the Japanese rat racer snake, Elaphe quadrivirgata, by the peroxidase and antiperoxidase technique. Vagal stimulation of VIP release has been observed in pigs (34). Exogenous VIP stimulated not only glucagon and insulin release in the dog in vivo (23) and from the perfused feline pancreas in situ (35), but also somatostatin release from the isolated canine pancreas (16). However, it is unlikely that such peptidergic transmission might be involved in the vagal stimulation of islet hormone secretion, because VIP is released by an atropineresistant mechanism during electrical vagal stimulation (34).

The possibility that the release of somatostatin increased by vagal stimulation occurred not from intraislet D cells but from somatostatin-containing peptidergic fibers running in the vagus is unlikely since SLI release induced by vagal nerve stimulation into the antral lumen of cats was not blocked by atropine (43).

Somatostatin can influence the release of acetylcholine from ganglionic cells in the gastrointestinal tract (12). The present results do not exclude the possibility that the somatostatin released by vagal stimulation of cholinergicmuscarinic receptors putatively located on islet D cells may directly inhibit the A, B and PPsecreting cells and also may indirectly inhibit their secretions by inhibiting further release of acetylcholine from the nerve terminals during vagal stimulation in a self-limiting fashion to modulate otherwise excessive secretion of glucagon, insulin and PP. If so, the parasympathetic nervous system might have a dual cholinergic mechanism in the broad regulation of the endocrine pancreatic function.

There are very few available data concerning sympathetic nerve control in the secretion of somatostatin and PP from the pancreatic islets. Bloom et al. (4) observed that an abrupt rise in arterial plasma levels of PP produced by an intravenous injection of 2-deoxyglucose or intense hypoxia was unaffected by prior section of the splanchnic nerves in conscious calves.

In the present study splanchnic nerve stimulation suppressed output of overall assayed pancreatic islet hormones into the pancreaticoduodenal vein transiently at the initial phase during the period of the stimulus along with a fall of pancreatic vein blood flow. Glucagon secretion was augmented after initial suppression during stimulation, whereas the release of insulin remained suppressed in the presence of marked hyperglycemia during stimulation and rebounded after the end of the stimulus.

PP secretion did not change after the initial fall during stimulation, and showed a delayed gradual increase toward the end of the experiment. Although this mechanism is difficult to be explained, it may be associated with experimental stress, in view of the similar delayed course to that of glucagon secretion.

Somatostatin secretion was moderately augmented after initial suppression during splanchnic nerve stimulation. This immediate fall may be attributed to the significant decrease in pancreatic venous plasma flow and to possible activation of $\alpha$-adrenergic receptors on D cells 
by rapid release of norepinephrine from sympathetic nerve terminals. The succeeding elevation of somatostatin output may be due to possible activation of $\beta$-adrenergic receptors of $D$ cells by released catecholamines during splanchnic nerve stimulation and to the concurrent marked hyperglycemia (17). In our results a significant rise was not seen in arterial plasma somatostatin in the presence of its augmented output during stimulation. This discrepancy may be explained by an extremely short half-life of the tetradecapeptide immunoreactivity in vivo (24). Samols and Weir (33) found that D cell secretion was inhibited by $\alpha$-adrenergic agonism and was stimulated by $\beta$-adrenergic agonism, like that of B cells, in the isolated canine pancreas with the exclusion of the duodenum from the perfusion circuit. They reported that $\alpha$-adrenergic agonism after $\beta$ adrenergic blockade moderately decreased somatostatin secretion and markedly decreased insulin release. In this regard it would be noteworthy that the basal pancreatic venous plasma concentrations, per se, of somatostatin and glucagon did not decrease at the initial phase even when the plasma flow fell, whereas those of PP and insulin were suppressed along with the plasma flow at the phase during splanchnic nerve stimulation.

We are grateful to Drs Hiroshi Kajinuma, Masaki Hayashi, Akira Itabashi, Tohru Yamaji and Yasunori Kanazawa for their valued advice. We are indebted to Miss Mariko Miyamoto and Miss Hiroko Shibayama for their technical assistance.

Received for publication 2 February 1981

\section{REFERENCES}

1. Adrian T. E., Bloom S. R., Bryant M. G., Polak J. M., Heitz P. H. and Barnes A. J. (1976) Distribution and release of human pancreatic polypeptide. Gut 17, 940-944

2. Arimura A., Sato H., Dupont A., Nishi N. and Schally A. V. (1975) Somatostatin: abundance of immunoreactive hormone in rat liver and pancreas. Science 189, 1007-1009

3. Bloom S. R., Edwards A. V. and Vaughan N. J. A. (1974) The role of the autonomic innervation in the control of glucagon release during hypoglycaemia in the calf. J. Physiol. 236, 611-623

4. Bloom S. R., Edwards A. V. and Hardy R. N. (1978) The role of the autonomic nervous system in the control of glucagon, insulin and pancreatic polypeptide release from the pancreas. J. Physiol. 280, 9-23
5. Chance R. E., Lin T. M., Johnson M. G., Moon N., Evans D. C., Jones W. E. and Koffenberger J. E. (1975) Studies on a newly recognized pancreatic hormone with gastrointestinal activities. Program Endocrin. Soc. No. 265, p. 183

6. Desbuquois B. and Aurbach G. D. (1971 Use of polyethylene glycol to separate free ana antibody-bound peptide hormones in radioimmunoassays. J. Clin. Endocrinol. 33, 732-738

7. Dubois P. M., Paulin C., Assan R. and Dubois M. P. (1975) Evidence for immunoreactive somatostatin in the endocrine cells of human foetal pancreas. Nature 256, 731-732

8. Feldman M., Richardson C. T., Taylor I. L. and WALSH J. H. (1979) Effect of atropine on vagal release of gastrin and pancreatic polypeptide. J. Clin. Invest. 63, 294-298

9. Floyd J. C., Fajans S. S., Pek S. and Chance R. E. (1977) A newly recognized pancreatic polypeptide; plasma levels in health and disease. Recent Progress in Hormone Research 33, 519570

10. Fuji S., Kobayashi S., Fujta T. and YanaiHARA N. (1980) VIP-immunoreactive nerves in the pancreas of the snake, Elaphe quadrivirgata (Boie): another model for insular neurosecretion. Biomedical Res. 1, 180-184

11. Fujita T. and Kobayashi S. (1979) Proposal of a neurosecretory system in the pancreas. An electron microscope study in the dog. Arch. Histol. Japon. 42, 277-295

12. Guillemin R. (1976) Somatostatin inhibits the release of acetylcholine induced electrically in the myenteric plexus. Endocrinology 99, 16531654

13. Guzman S., Chayvialle J.-A., Banks W. A., RAYFord P. L. and THOMPSON J. C. (1979) Effect of vagal stimulation on pancreatic secretion and on blood levels of gastrin, cholecystokinin, secretin, vasoactive intestinal polypeptide, and somatostatin. Surgery 86, 329-336

14. Harris V., Conlon J. M., Srikant C. B., MCCORKLE K., Schusdziarra V., IpP E. and UNGER R. H. (1978) Measurements of somatostatin-like immunoreactivity in plasma. Clin. Chim. Acta 87, 275-283

15. Ipp E., Dobbs R. E., Harris V., Arimura A., VALE W. and Unger R. H. (1977) The effects of gastrin, gastric inhibitory polypeptide, secretin, and the octapeptide of cholecystokinin upon immunoreactive somatostatin release by the perfused canine pancreas. J. Clin. Invest. 60, 1216-1219

16. IPP E., Dobis R. E. and Unger R. H. (1978) Vasoactive intestinal peptide stimulates pancreatic somatostatin release. FEBS Letters 90, 76-78

17. IpP E., Dobbs R. E., Arimura A., Vale W., HARRIS V. and UNGER R. H. (1977) Release of immunoreactive somatostatin from the pancreas in response to glucose, amino acids, pan- 
creozymin-cholecystokinin, and tolbutamide. J. Clin. Invest. 60, 760-765

18. IVERSEN J. (1973) Effect of acetylcholine on the secretion of glucagon and insulin from the isolated, perfused canine pancreas. Diabetes 22, 381-387

19. Kaneto A., Miki E. and Kosaka K. (1974) Effects of vagal stimulation on glucagon and insulin secretion. Endocrinology 95, 1005-1010

20. Kaneto A., Kajinuma $\mathbf{H}$. and Kosaka $\mathbf{K}$. (1975) Effect of splanchnic nerve stimulation on glucagon and insulin output in the dog. Endocrinology 96, 143-150

21. Kaneto A. and KosaKa K. (1974) Stimulation of glucagon and insulin secretion by acetylcholine infused intrapancreatically. Endocrinology 95, 676-681

22. Kaneto A., Sato H., Kaneko T., Yanaihara C., Yanalhara $N$. and Kosaka K. (1981) Stimulation of somatostatin, pancreatic polypeptide, glucagon and insulin secretion by acetylcholine infused intrapancreatically. Biomedical Res. 2, 57-66

23. Kaneto A., Kaneko T., Kajinuma H. and KoSAKA K. (1977) Effect of vasoactive intestinal polypeptide infused intrapancreatically on glucagon and insulin secretion. Metabolism 26, 781-786

24. Kastin A. J., CoY D. H., Jacquet Y., Schally A. V. and Plotnikoff N. P. (1978) CNS effects of somatostatin. Metabolism 27, Suppl. 1, 1247-1252

25. Larsson L.-I., Sundler F. and Håkanson P. (1976) Pancreatic polypeptide-a postulated new hormone: identification of its cellular storage site by light and electron microscopic immunocytochemistry. Diabetologia 12, 211226

26. Larsson L.-I., Fahrenkrug J., Holst J. J. and Schaffalitzky de Muckadell O. B. (1978) Innervation of the pancreas by vasoactive intestinal polypeptide (VIP) immunoreactive nerves. Life Sci. 22, 773-779

27. Luft R., Efendić S., HöKfelt T., Johansson O. and ARIMURA A. (1974) Immunohistochemical evidence for the localization of somatostatinlike immunoreactivity in a cell population of the pancreatic islets. Med. Biol. 52, 428-430

28. Mcintosh C., Arnold R., Bothe E., Becker H., Kobberling J. and Creutzfeldt W. (1978) Gastrointestinal somatostatin in man and dog. Metabolism 27, Suppl. 1, 1317-1320

29. Morgan C. R. and Lazarow A. (1963) Immunoassay of insulin: two antibody system. Plasma insulin levels of normal, subdiabetic and diabetic rats. Diabetes 12, 115-126

30. OrCi L., Baetens D., Dubois M. P. and RUFENER C. (1975) Evidence for the D-cell of the pancreas secreting somatostatin. Horm. Metab. Res. 7, 400-402

31. Ørskov H., Thomsen H. G. and Yde H. (1968)
Wick chromatography for rapid and reliable immunoassay of insulin, glucagon and growth hormone. Nature 219, 193-195

32. SAID S. I. and Rosenberg R. N. (1976) Vasoactive intestinal polypeptide: abundant immunoreactivity in neural cell lines and normal nervous tissue. Science 192, 907-908

33. Samols E. and WeIr G. C. (1979) Adrenergic modulation of pancreatic A, B, and D cells. J. Clin. Invest. 63, 230-238

34. Schaffalitzky de Muckadell O. B., FAHrenkrug J. and Holst J. J. (1977) Release of vasoactive intestinal peptide by electric stimulation of the vagal nerves. Gastroenterology 72, 373-375

35. Schbalin M., Said S. I. and Makhlouf G. M. (1977) Stimulation of insulin and glucagon secretion by vasoactive intestinal peptide. Amer. J. Physiol. 232, E197-E200

36. Schwartz T. W., Holst J. J., Fahrenkrug J., Jensen S. L., Nielsen O. V., Rehfeld J. F., Schaffalitzky de Muckadell O. B. and STAdIL F. (1978) Vagal and cholinergic regulation of pancreatic polypeptide secretion. J. Clin. Invest. 61, 781-789

37. Schwartz T. W., Rehfeld J. F., Stadil F., Larsson L.-I., Chance R. E. and Moon N. (1976) Pancreatic-polypeptide response to food in duodenal ulcer patients before and after vagotomy. Lancet I, 1102-1105

38. Schwartz T. W., Stenquist B. and Olbe L. (1979) Cephalic phase of pancreatic-polypeptide secretion studied by sham feeding in man. Scand. J. Gastroent. 14, 313-320

39. Schwartz T. W. and Rehfeld J. F. (1977) Mechanism of pancreatic-polypeptide release. Lancet I, 697-698

40. Taylor I. L., Feldman M., Richardson C. T. and WALSH J. H. (1978) Gastric and cephalic stimulation of human pancreatic polypeptide release. Gastroenterology 75, 432-437

41. UVNÄS-WALlENSTEN K., ReHFELD J. F., LARSSON L.-I. and UvNÄs B. (1977) Heptadecapeptide gastrin in the vagal nerve. Proc. Natl. Acad. Sci. 74, 5707-5710

42. Uvnäs-Wallensten K., Efendić S. and LufT R. (1977) Inhibition of vagally induced gastrin release by somatostatin in cats. Horm. Metab. Res. 9, 120-123

43. Uvnäs-Wallensten K., Efendić S. and LufT R. (1978) The occurrence of somatostatin-like immunoreactivity in the vagal nerves. Acta Physiol. Scand. 102, 248-250

44. Vaysse N., Bastie M. J., Pascal J. P., Roux P., Martinel C. N., Lacroix A. and Ribet A. (1975) Role of cholinergic mechanisms in the response to secretin of isolated canine pancreas. Gastroenterology 69, 1269-1277

45. Washro M. E. and Rice E. W. (1961) Determination of glucose by an improved enzymatic procedure. Clin. Chem. 7, 542-545 